\title{
Assistência à mulher com câncer de colo uterino: o papel da enfermagem
}

\author{
Health care to the women with cervical cancer: the role of nursing
}

\author{
Scheila Frigato' e Luiza Akiko Komura Hoga²
}

\section{Resumo}

O tratamento do câncer de colo de útero, sobretudo a radioterapia e a quimioterapia, provocam uma série de conseqüências físicas e emocionais na mulher. São descritas as formas de tratamento radioterápico, que inclui a teleterapia e a braquiterapia, e quimioterápico realizados junto às mulheres acometidas pelo câncer de colo de útero atendidas nos Serviços de Radioterapia e Oncologia Clínica do Instituto de Radiologia do Hospital das Clínicas da Faculdade de Medicina da Universidade de São Paulo (HC-FMUSP). As pacientes submetidas a estes tratamentos recebem assistência de equipe multiprofissional na qual a enfermagem assume papel importante no suporte e orientação à mulher e sua família. $\mathrm{O}$ presente artigo tem como objetivo relatar a assistência prestada a estas mulheres e respectivos familiares, com ênfase no papel desempenhado pela equipe de enfermagem. São descritas as orientaçôes relativas às reações adversas em pele e mucosas do trato gastro-intestinal e urinário, os cuidados locais adequados e esclarecimento de dúvidas. Além de informar e tranqüilizar o paciente e seus familiares, a enfermagem pode minimizar, através de triagem prévia, a necessidade de maior frequiência da avaliação médica. Palavras-chave: neoplasias do colo uterino; radioterapia; braquiterapia; quimioterapia; enfermagem.

\section{Abstract}

The treatment of cervix cancer, especially radiotherapy and chemotherapy, cause a series of physical and emotional consequences in women. Here are depicted the forms of radiotherapic treatment (that include teletherapy and brachitherapy) and chemotherapy carried out in women with cervix cancer treated in the Radiotherapy Service and the Oncology Clinic of the Radiology Institute of the Hospital das Clínicas da Faculdade de Medicina da Universidade de São Paulo (HC-FMUSP). The patients submitted to these treatments receive care from a multiprofessional team, in which nursing takes an important role in the support and orientation of women and their families. The present article has the objective of reporting the care given to these women and their families, stressing the role taken by the nursing team. Here are depicted the orientations for the adverse reactions in skin and mucous membrane of the gastro intestinal and urinary systems, with the adequate care of the site and answering of the questions. In addition to inform and reassure the pacients and their families, nursing can minimize, trough previous selection, the need of a more frequent medical visits.

Key words: cervix neoplasms; radiotherapy; brachytherapy; chemotherapy; nursing.

${ }^{1}$ Enfermeira do Ambulatório de Oncologia e Radioterapia do Hospital das Clínicas da Faculdade de Medicina da Universidade de São Paulo (HC-FMUSP). Mestranda em Enfermagem da Escola de Enfermagem da Universidade de São Paulo (EE-USP)

${ }^{2}$ Enfermeira Obstétrica. Livre-Docente em Enfermagem. Professora associada do Departamento de Enfermagem Materno-Infantil e Psiquiátrico da EE-USP.

Departamento: Divisão de Oncologia Clínica, Serviços de Radioterapia e Oncologia Clínica do Instituto de Radiologia do Hospital das Clínicas da Faculdade de Medicina da Universidade de São Paulo (HC-FMUSP).

Autor responsável: Scheila Frigato

Endereço: Rua Oscar Freire, 1518 - apt ${ }^{\circ} 121$ CEP: 05409-010 - Jardim América - SP

Telefone: (0xx11) 3069-6741/ 9595-7038 


\section{INTRODUÇÃO}

A Organização Mundial de Saúde (OMS) estima que o câncer atinge anualmente pelo menos 9 milhões de pessoas, e cerca de 5 milhōes morrem em decorrência da doença. Atualmente ela é a segunda causa de morte por doença na maioria dos países, sendo superada apenas pela doença cardiovascular ${ }^{1}$.

O colo do útero é, depois do câncer de mama, a segunda localização anatômica mais freqüente do câncer na população feminina no Brasil e é responsável por $15 \%$ das ocorrências de tumores malignos em mulheres2. Em 1999, foram registrados 31.200 novos casos de câncer de mama e 20.600 de colo de útero ${ }^{1}$.

Considera-se que a infecção pelo Papiloma Vírus Humano (HPV) representa o principal fator de risco para o câncer de colo de útero. Outros fatores foram identificados como de risco, como os sócio-econômicos e ambientais e os hábitos de vida, que incluem o início precoce da atividade sexual, a pluralidade de parceiros sexuais, o tabagismo, os hábitos inadequados de higiene e o uso prolongado de contraceptivos orais.

Em estágios iniciais o câncer de colo uterino é assintomático, e a descoberta da doença se faz por meio do resultado do exame citopatológico (Papanicolaou) que deve ser feito regularmente. Quando o câncer não é diagnosticado em sua fase inicial, já existe invasão grosseira do colo uterino e de tecidos adjacentes, podendo apresentar sintomas como sangramento durante a relação sexual e dispareunia.

A abordagem mais efetiva para o controle do câncer do colo do útero é o rastreamento por meio do exame citopatológico. Cabe aos profissionais de saúde orientar a população feminina quanto à importância da realização periódica deste exame para o diagnóstico precoce da doença, pois isto possibilita o tratamento em fase inicial e, conseqüentemente, diminuição da morbimortalidade por este tipo de câncer.

A conduta terapêutica para lesão neoplásica maligna do colo de útero se fundamenta no diagnóstico, estadiamento e prognóstico da doença ${ }^{3}$. A partir do diagnóstico, realizado por meio de biópsia, o tratamento é indicado tendo como parâmetro a avaliação da localização, tamanho e tipo histológico do tumor, a idade e as condiçōes gerais de saúde da mulher.

Quando a doença se encontra no seu estadiamento inicial, a cirurgia possibilita a remoção completa do tumor e propicia maiores chances de cura. A indicação da associação da radioterapia e/ou quimioterapia ao tratamento é decidida com base no estadiamento da doença e nas características tumorais ${ }^{3}$.

Nos casos avançados, em que o tumor já atingiu estruturas adjacentes ao útero, o tratamento de eleição é a radioterapia associada à braquiterapia. A quimioterapia no câncer do colo do útero é indicada concomitante à radioterapia, como radiossensibilizante, o que permite aumentar o controle local e a sobrevida livre de doençá ${ }^{4}$ É realizada também na ocorrência de recidiva, quando não há a possibilidade da cirurgia e/ ou da radioterapia. Como se tratam de drogas nefrotóxicas e causadoras de mielodepressão, é essencial que mulheres submetidas a estes tratamentos tenham suas funçōes renal e hematológica preservadas 5 .

Os cuidados paliativos às pacientes em seguimento por meio destes tratamentos devem incluir a abordagem da dor e outros sintomas, associados ou não a ela, como a anorexia, obstrução ureteral e intestinal, obstipação, tosse, dispnéia, hipercalcemia, alteraçooes mentais, náuseas e depressão. Os familiares das pacientes também necessitam de orientação quanto aos sintomas mais comuns apresentados pelas pacientes em fase terminal da doença, para que possam prestar cuidados da forma mais adequada possível'5.

Nos Serviços de Oncologia Clínica e Radioterapia do Hospital das Clínicas da Faculdade de Medicina da Universidade de São Paulo (HC-FMUSP), a assistência às pacientes com câncer de colo de útero submetidas ao tratamento rádio- e quimioterápico é prestada por equipe multiprofissional composta por médico, enfermeiro, nutricionista, assistente social, físico, auxiliar de enfermagem e técnico de radiologia.

O presente artigo tem por objetivo relatar a assistência prestada a estas mulheres, com ênfase aos cuidados de enfermagem desenvolvidos no processo de assistência.

\section{RADIOTERAPIA}

A radioterapia utiliza radiação ionizante (radiações que têm energia suficiente para ionizar moléculas através da liberação de elétrons da estrutura atômica, como por exemplo os raios $\mathrm{X}$, partículas beta, partículas alfa, etc) para o tratamento de câncer e algumas doenças benignas. A radioterapia atua no ácido desoxirribonucléico (DNA) das células, impedindo-a de se multiplicar (morte reprodutiva) e/ou induzindo sua morte direta por apoptose. As células normais também sofrem danos em seu DNA, contudo possuem possibilidade de reparo com maior eficiência que a célula maligna. Dessa forma são obtidos resultados positivos, por meio da eliminação total ou parcial dos tumores tratados com radiação ${ }^{6}$.

Trata-se de um tratamento localizado, sendo uma das modalidades mais utilizadas no tratamento do câncer de colo uterino, associada ou não à cirurgia. A quimioterapia, por sua vez consiste em um tratamento sistêmico ${ }^{7}$. 
A aplicação da radioterapia é realizada basicamente de duas formas: a externa, denominada teleterapia, e a interna, braquiterapia. Na teleterapia, o feixe de radiação ionizante é apontado para a região-alvo do corpo denominada campo, a uma distância determinada; na braquiterapia o elemento radioativo é colocado próximo, em contato ou dentro do órgão a ser tratado.

$\mathrm{O}$ tratamento com radioterapia complementada pela braquiterapia intra-uterina possibilita a cura de cerca de 60 a $90 \%$ dos casos de câncer de colo de útero que se encontram em estadiamento inicial. Nos estadiamentos intermediários e avançados da doença são utilizadas a radioterapia externa e a braquiterapia, que quando associadas, possibilitam a cura de cerca de 30 a $60 \%$ dos casos ${ }^{8}$.

\section{Teleterapia}

A radioterapia externa ou teleterapia utiliza fontes radioativas de origem nuclear (como os aparelhos de Cobalto-60, que possuem uma fonte de Cobalto em seu interior) ou aceleradores lineares, que produzem radiação por meio da aceleração de elétrons.

Antes do início das aplicaçôes de radioterapia externa, os membros da equipe multiprofissional fazem um planejamento do tratamento a ser realizado. São definidos o local a ser tratado e a melhor estratégia a ser seguida, que incluem decisóes relativas à dose, o intervalo do tratamento assim como a data de início e o horário das aplicações. A dose total é fracionada em aplicaçôes diárias, cinco vezes por semana, durante cinco a seis semanas. A dose diária de radiação é subdividida em 4 campos da região pélvica (local do tratamento), sendo um anterior, um posterior e dois laterais.

Durante o planejamento são feitas marcas à tinta na pele da paciente para delimitar o local a ser tratado. A paciente é orientada a manter estas marcas até o final do tratamento, embora possa continuar tomando banho como de hábito, mas com o cuidado de não esfregar a pele da região demarcada. Elas são também esclarecidas quanto ao fato de, caso as marcas deixem de ser nítidas, estas deverem ser reforçadas pelo técnico. Ao término das aplicações, as marcas podem ser retiradas pela lavagem cuidadosa do local, com a finalidade de não provocar lesões na pele.

A região corpórea irradiada, a energia usada no tratamento, o estado geral e a idade da mulher são fatores determinantes da gravidade e do início dos efeitos colaterais que, em sua grande maioria, são locais e específicos. Antes do início do tratamento, a paciente e seus familiares recebem orientações da enfermeira relativas ao tratamento: os possíveis efeitos colaterais, o início de sua ocorrência, seu tempo de duração e principalmente, sobre as medidas a serem adotadas para minimizar essas conseqüências.

Em nosso Serviço, as pacientes são avaliadas semanalmente pelo seu médico durante o tratamento. Entretanto, no contato diário com a equipe, o papel da enfermagem é fundamental na orientação do paciente, minimizando, através de triagem prévia, a necessidade de avaliações médicas com maior freqüência.

Os efeitos colaterais da radioterapia incluem reações de pele, sensação de cansaço e alterações do apetite. As pacientes são orientadas quanto ao tratamento propriamente dito, ou seja, que é localizado e que produz efeitos limitados à área irradiada, por exemplo, reaçôes como vermelhidão, escurecimento da pele ou descamação do local tratado. No caso de aparecimento de descamação ou ulceração, há necessidade de procura da enfermeira do setor para recebimento de novas orientaçōes. O perigo da automedicação é alertado, assim como a não aplicação de loção, creme, talco ou desodorante na área de tratamento sem orientação, pelo fato destes produtos poderem conter em sua composição substâncias que podem interferir com a penetração da dose recebida e aumentar os efeitos colaterais na pele.

Quanto às possíveis lesōes na pele, são reforçadas as orientaçôes relativas a evitar coçar a região tratada para prevenir irritações, lavar o local com água morna e sabonete neutro e não utilizar esparadrapo ou adesivos sobre a pele irradiada. Destaca-se a preferência para o uso de tecidos de fibra natural, como os de algodão, evitando roupas justas ou feitas com tecido sintético. A orientações incluem também evitar a exposição aos extremos de temperatura provocados pelos aparelhos de aquecimento e ar condicionado, a exposição da área tratada ao sol durante 6 meses após o término do tratamento, protegendo a pele com vestuário e aplicação de protetor solar.

Além destes, elas recebem alertas quanto à realização de exame periódico sistemático da pele em busca de lesões e/ou sinais de infecção, ingestão de pelo menos 2 litros de líquidos por dia e a preferência aos alimentos ricos em calorias e proteínas. Podendo ocorrer cansaço e sonolência durante o tratamento, é recomendado o repouso com manutenção das atividades diárias na medida de suas possibilidades.

Os efeitos colaterais específicos do tratamento radioterápico estão associados à região do corpo em que a radiação é aplicada. No caso da irradiação do colo do útero, pode ocorrer diarréia e disúria, reversíveis, e amenorréia, que é permanente. A mulher submetida à radioterapia de pelve é orientada a manter a atividade sexual após o tratamento desde que se sinta bem, pois a vagina pode ficar ressecada e menos flexível. 
Nestes casos deve-se utilizar lubrificantes vaginais à base de água nas relações sexuais para diminuir o desconforto, e orientar que discreto sangramento vaginal nas primeiras relaçōes é normal. $\mathrm{Na}$ ocorrência de diarréia ou disúria, estas devem ser comunicadas imediatamente à equipe assistencial.

\section{Braquiterapia}

Existem duas modalidades de tratamento braquiterápico. A de alta taxa de dose (High Dose Rate $H D R)$ é fracionada, utiliza programação via computador, e tempo menor de exposição à radiação, o que possibilita tratamento ambulatorial. A baixa taxa de dose (Low Dose Rate - $L D R)$ é um tratamento contínuo, com tempo de exposição maior, o que demanda a internação hospitalar da paciente, expondo a equipe à radiação.

A finalidade da radioterapia é o tratamento do tumor com preservação das estruturas anatômicas vizinhas não afetadas pela doença, na medida do possível. $\mathrm{Na}$ braquiterapia a radiação é aplicada diretamente no local do tumor, através de moldes, cateteres ou implantes, o que possibilita irradiar volumes-alvo pequenos com alta dose de radiação. Este método permite poupar estruturas vizinhas não afetadas pela doença, pois existe uma queda importante da dose à medida que se afasta das fontes. A alta dose de radiação administrada ao colo uterino aumenta as chances de cura desse tipo de tumor.

A braquiterapia de colo de útero pode ser utilizada como um tratamento exclusivo ou como complemento da radioterapia externa. No Ambulatório de Radioterapia do HC-FMUSP é realizada somente a braquiterapia de alta taxa de dose (HDR).

A paciente segue um plano de tratamento ambulatorial que consiste na aplicação de quatro frações de braquiterapia com intervalo semanal e duração de aproximadamente 50 minutos, que se inicia geralmente enquanto a mulher ainda se encontra em tratamento com teleterapia.

O material necessário para este tratamento consiste nos aplicadores ginecológicos, sonda tipo Foley, pinças tipo Cheron, Pozzi e Kelly, histerômetro, espéculos, cúpula com anti-séptico à base de Iodo, gaze esterilizada, anestésico tópico em gel e contraste iônico. Este conjunto de materiais é disposto sobre uma mesa, preparada previamente pelo auxiliar de enfermagem. Cabe a este profissional prestar ajuda ao radioterapeuta durante a realização do procedimento.

A paciente a ser submetida à braquiterapia é colocada em posição ginecológica, vestida com um avental de algodão e coberta por um lençol, sendo exposta apenas sua regiáo genital. Ela é orientada a retirar todos os adornos desnecessários assim como as próteses, caso existam, antes de adentrar a sala de tratamento. Após assepsia, o radioterapeuta faz a sondagem vesical introduzindo sonda do tipo Foley de 2 vias e injeta o contraste no balonete para verificar a posição da bexiga na radiografia de planejamento da braquiterapia. A seguir, coloca os aplicadores ginecológicos no útero e vagina, que servirão como meio de condução para a semente de Iridium-192, acondicionada no aparelho de HDR, que é teleguiada pelo computador.

Uma vez encerrada esta etapa do procedimento, o técnico de radiologia realiza radiografias pélvicas nos sentidos antero-posterior e latero-lateral para que o radioterapeuta possa confirmar a posição correta dos aplicadores e realizar o planejamento. O físico então calcula o tempo necessário para administrar a dose de tratamento prescrita pelo médico e, por meio da programação computadorizada do equipamento, o material radioativo é inserido nos aplicadores e a radiação é liberada.

A sensação dolorosa durante a colocação dos aplicadores é uma queixa freqüente das pacientes. Em razão disso, previamente ao início do procedimento, é feita uma punção venosa periférica e instalado soro glicosado a $5 \%$ para facilitar a administração de medicamentos antiespasmódicos e/ou analgésicos. As pacientes são orientadas a manter jejum de 8 horas, fazer tricotomia pubiana e providenciar um acompanhante adulto para o retorno à sua residência.

Mulheres acometidas pelo câncer se encontram fragilizadas e sensíveis. Portanto, no decorrer do tratamento de braquiterapia, que é predominantemente invasiva, a condição de fragilidade se potencializa e este fato demanda atenção especial dos componentes da equipe multiprofissional envolvidos com seu tratamento.

É importante orientar a mulher submetida à braquiterapia em relação ao tratamento a ser realizado para diminuir a ansiedade e a sensação de insegurança que são inerentes ao processo. Estas mulheres devem estar cientes de que, após a braquiterapia, há possibilidade da ocorrência de sangramentos vaginais discretos em conseqüência da manipulação do local, porém, a persistência da sensação dolorosa ou de outros sintomas não são ocorrências habituais após o tratamento.

As mulheres que não apresentam intercorrências durante o tratamento podem manter suas atividades sexuais durante o tratamento. Porém, elas devem estar cientes de que esta prática não é recomendada, sobretudo por motivos de higiene e para evitar eventuais traumatismos locais. Após a radioterapia, ela deve retomar as suas atividades sexuais habituais a fim de preservar funcionalmente a vagina. Deve estar orientada 
quanto ao fato de, meses após o tratamento, poder ter a vagina mais estreitada, menos maleável e ressecada, o que pode ocasionar desconforto e sangramento discreto no momento do coito. Após a braquiterapia, a mulher pode desenvolver estenose vaginal se não tiver vida sexual ativa, devendo ser orientado o uso de dilatadores vaginais.

A função ovariana é abolida, ocasionando amenorréia e eventualmente o aparecimento dos sintomas de menopausa, como a sensação de ondas de calor. A paciente deve estar ciente da possibilidade de o médico recorrer à reposição hormonal caso ocorra tais sintomas.

Reações tardias podem aparecer após meses ou anos do término do tratamento. As principais são as chamadas retites, causadoras de sangramento, dor e dificuldade de evacuar ou as cistites actínicas, que provocam disúria, hematúria ou incontinência urinária. São reações possíveis de serem solucionadas pelo uso de medicamentos ou requererem até mesmo uma cirurgia, quando os sintomas forem graves.

\section{QUIMIOTERAPIA}

A quimioterapia tem sido utilizada com freqüência como tratamento adjuvante à radioterapia devido aos sucessos alcançados por essa associação. Estes resultados positivos se devem ao fato de a quimioterapia potencializar os efeitos da radioterapia e tornar mais eficiente o processo de combate à célula tumoral. A medicação mais utilizada no Ambulatório de Oncologia do HC-FMUSP tem sido a cisplatina, aplicada semanalmente e concomitante à radioterapia.

$\mathrm{O}$ tratamento com quimioterapia atinge tanto as células normais quanto as neoplásicas e afeta principalmente as células de reprodução rápida, como as da medula óssea, da mucosa intestinal e dos folículos pilosos. A ação nociva contra as células normais acarreta muitos efeitos colaterais.

A cisplatina é aplicada por infusão endovenosa contínua e trata-se de droga ciclo-celular não específica, que produz ligações cruzadas no DNA e inibe a sua síntese. Ela provoca efeitos colaterais como a mielodepressão, náuseas e vômitos severos, neuropatia periférica, ototoxicidade, nefrotoxicidade e fadiga?

A mielodepressão pode ser leve ou moderada, porém quando associada à radioterapia pode se tornar severa. A paciente é orientada quanto aos sinais e sintomas de infecção, assim como quanto à necessidade de procurar o médico se a temperatura corporal for maior que $37,7^{\circ} \mathrm{C}$. A ocorrência de febre entre o $7^{\circ}$ e o $14^{\circ}$ dia após a aplicação de quimioterapia deve ser valorizada, pois pode ser indício de infecção. As mulheres são orientadas também a evitar aglomeraçóes e contato com pessoas doentes, a manter boa higiene oral e corporal, evitar quedas e ferimentos, recorrer ao médico caso apareça algum sinal ou sintoma de sangramento, utilizar escova dental de cerdas macias, manter alimentação adequada e higienizar os alimentos antes de seu consumo.

Náuseas e vômitos são efeitos colaterais incômodos que podem ser apresentados pelas pacientes. $\mathrm{Na}$ ocorrência deles, as pacientes são encorajadas a ingerir pequenas porçôes de alimentos leves, com maior freqüência. São orientadas a ingerir alimentos frios ou à temperatura ambiente, para atenuar seu aroma e sabor, tomar as medicações antieméticas prescritas em intervalos regulares, evitar alimentos muito doces, gordurosos, salgados ou temperados, ou com odor forte e, na ausência de medicação prescrita, discutir esta questão com a enfermeira. Elas devem estar cientes de que devem procurar o médico quando do aparecimento de indícios de sangue no vômito.

A quimioterapia e a radioterapia aplicada na região pélvica causam diarréia como efeito colateral e, em razão deste problema, as pacientes são orientadas a ingerir alimentos ricos em proteínas, calorias e potássio, e pobres em fibras e farelos. Alimentos com estas características incluem o queijo fresco, ovos, batatas, arroz, cereais, bananas, macarrão, torradas, entre outros. Elas são também orientadas à ingestão hídrica de pelo menos 2 litros por dia; lavagem da região anal com sabonete neutro após cada evacuação, evitando o uso de papel higiênico, seguimento criterioso da medicação prescrita e à procura do médico caso aumente a freqüência das evacuaçôes, mude a consistência ou quando se observa presença de sangue nas fezes.

Além disso, as pacientes em tratamento quimioterápico com cisplatina devem estar cientes de que devem procurar o médico caso apresentem sintomas como formigamentos, tremores, sensação de choque e alterações de sensibilidade nas mãos e pés, perda de audição, com atenção especial à necessidade da ingestão hídrica para prevenção da nefrotoxicidade.

\section{CONSIDERAÇÕES FINAIS}

$\mathrm{Na}$ atualidade o papel do profissional atuante na área de oncologia não se restringe à ajuda à família na convivência com a morte, que pode ocorrer de forma rápida e previsível. Cabe a este profissional, além da ação terapêutica propriamente dita, dar suporte às pacientes oncológicas para o enfrentamento da doença, pois o câncer requer tratamento prolongado e é passível de efeitos adversos. Este conjunto provoca transformações nas relações sociais e pessoais da mulher e sua família o que requer atenção e suporte por parte 
dos profissionais, sobretudo da enfermagem ${ }^{10}$.

Pacientes com câncer de colo de útero se encontram fragilizadas e ansiosas com o diagnóstico, prognóstico e com as mudanças na vida pessoal e familiar provocadas pela doença. Muitas mulheres desejam aprender tudo o que puderem sobre sua doença, as opções de tratamento, a ação dos quimioterápicos, os efeitos da radiação nas células e suas conseqüências, e sobre os aparelhos utilizados no decorrer do tratamento. Agindo desta forma se tornam participantes ativas nas decisóes relacionadas aos seus cuidados.

Cabe ao enfermeiro indicar e fornecer orientaçōes relativas às medidas preventivas, identificar precocemente os efeitos colaterais do tratamento a fim de minimizá-los, orientar e acompanhar a paciente e respectiva família e manter em mente que as açôes de enfermagem devem ser individualizadas, considerandose suas características pessoais e sociais. É de grande ajuda a disponibilização de orientaçōes gerais na forma impressa, pois este recurso auxilia no processo de orientação e esclarecimento da própria mulher e de seus familiares. Ele permite reforçar e garantir acesso fácil às orientações fornecidas durante a consulta de enfermagem.

Ressalta-se a importância do preparo do enfermeiro na orientação e oferecimento de cuidados específicos às pacientes com câncer. Isto demanda a necessidade do conhecimento dos últimos avanços na área do tratamento, independentemente da estrutura na qual está inserido ${ }^{11}$.

Acredita-se que a disseminação do conhecimento do tratamento de radioterapia e quimioterapia tal como é realizado no Ambulatório de Radioterapia e Oncologia do HC-FMUSP e o respectivo papel da enfermagem possa ser de grande valia para os profissionais atuantes na área correlata.

\section{REFERÊNCIAS BIBLIOGRÁFICAS}

1. Ministério da Saúde. Secretaria Nacional de Assistência à Saúde. Instituto Nacional de Câncer (Brasil). Estimativa da incidência e mortalidade por câncer no Brasil para 1999. Rio de Janeiro: INCA; 1999.

2. Ministério da Saúde. Instituto Nacional de Câncer (Brasil). Câncer no Brasil: dados dos registros de base populacional. Rio de Janeiro: INCA; 1991.

3. Chambô Filho A, Cohen MCPM, Cardoso PS. Câncer de colo, estádio IB: alternativas de tratamento. Femina 2001;29(9):631-3.

4. Rose PG, Bundy BN, Watkins EB, Thigpen JT, Deppe G, Maiman MA, et al. Concurrent cisplatin-based radiotheraphy and chemotherapy for locally advanced cervical cancer. N Engl J Med 1999;340:1144-53.

5. Pereira Primo WQS. Tratamento do câncer avançado do colo do útero. Femina 2000;30(8):525-8.

6. Segreto RA, Segreto HRC. Radiação ionizante e resposta celular: atualidades. Radiol Bras 1997;30:301-7.

7. Clarck JC, McGee RF. Enfermagem oncológica: um curriculum básico. 2a ed. Porto Alegre: Artes Médicas; 1997.

8. Leibel SA, Phillips TL. Textbook of radiation oncology. 1st ed. Philadelphia: WB Saunders; 1998.

9. Bonassa EMA. Enfermagem em terapêutica oncológica. 2a ed. São Paulo: Atheneu; 2000.

10. Lima RAG. A enfermagem na assistência à criança com câncer. Goiânia: AB; 1995 .

11. Diegues SRS, Pires AMT. A atuação do enfermeiro em radioterapia. Rev Bras Cancerol 1997;43(4):251-5. 